\title{
Adubação potássica em arroz irrigado conforme a capacidade de troca catiônica do solo
}

\author{
Ibanor Anghinoni(1), Felipe de Campos Carmona(2), Silvio Aymone Genro Junior(2) e Madalena Boeni( ${ }^{(2)}$
}

(1)Universidade Federal do Rio Grande do Sul, Departamento de Solos, Avenida Bento Gonçalves, no 7.712, CEP 91501970 Porto Alegre, RS, Brasil. E-mail: ibanghi@ufrgs.br (2)Instituto Rio Grandense do Arroz, Avenida Bonifácio Carvalho Bernardes, o 1.494, Caixa Postal 29, CEP 94930030 Cachoeirinha, RS, Brasil. E-mail: felipe.c.carmona@gmail.com, genrojr@yahoo.com.br, madaboeni@hotmail.com

Resumo - O objetivo deste trabalho foi avaliar a resposta do arroz irrigado por inundação à aplicação de doses de potássio, conforme a capacidade de troca catiônica (CTC) do solo. Foram utilizados 16 solos com diferentes valores de $\mathrm{CTC}$ a pH 7,0 $\left(\mathrm{CTC}_{\mathrm{pH} 7}\right)$, divididos em duas classes: solos com $\mathrm{CTC}_{\mathrm{pH} 7}$ até $15 \mathrm{cmol}_{\mathrm{c}} \mathrm{dm}^{-3}$ e com $\mathrm{CTC}_{\mathrm{pH} 7}$ maior que esse valor. O experimento foi realizado nas safras agrícolas de 2005/2006 e 2006/2007, em oito locais por ano agrícola, com uso de diferentes cultivares de arroz, conforme o local ou o ano. Foram calculados os incrementos médios da produtividade de arroz pela aplicação das doses de K, em função da razão $\mathrm{K} / \mathrm{CTC}_{\mathrm{pH} 7}$. A dose de máxima eficiência econômica (DMEE) de potássio foi calculada de acordo com os preços do fertilizante e do arroz, praticados de 2003 a 2012. O arroz respondeu de forma econômica à aplicação de potássio, em ambas as classes de $\mathrm{CTC}_{\mathrm{pH} 7}$ utilizadas, com maior incremento de produtividade nos solos com menor relação $\mathrm{K} / \mathrm{CTC}_{\mathrm{pH} 7}$. Na média dos dez anos, a DMEE foi sempre superior a U\$ 100,00 e maior nos solos com $\mathrm{CTC}_{\mathrm{pH}}>15,0 \mathrm{cmol}_{\mathrm{c}} \mathrm{dm}^{-3}$.

Termos para indexação: Oryza sativa, calibração, eficiência econômica, recomendação de adubação, saturação da CTC.

\section{Potassium fertilization in flooded rice according to soil cation exchange capacity}

\begin{abstract}
The objective of this work was to evaluate the response of flooded rice to the application of potassium doses, according to the soil cation exchange capacity (CEC). Sixteen soils with different CEC at $\mathrm{pH} 7.0\left(\mathrm{CEC}_{\mathrm{pH} 7}\right)$, divided in two classes, were used: soils with $\mathrm{CEC}_{\mathrm{pH} 7}$ up to $15 \mathrm{cmol}_{\mathrm{c}} \mathrm{dm}^{-3}$ and $\mathrm{CEC}_{\mathrm{pH} 7}$ higher than this value. The experiment was carried out in the crop seasons of 2005/2006 and 2006/2007, in eight places per crop year, using different rice cultivars, according to the place or year. The average increment in rice production due to the applied doses of $\mathrm{K}$ was calculated, according to the $\mathrm{K} / \mathrm{CEC}_{\mathrm{pH} 7}$ ratio. The potassium maximum economic efficiency dose (MEED) was calculated according to the prices of the fertilizer and rice, practiced from 2003 to 2012. Rice responded economically to potassium fertilization, in both soil $\mathrm{CEC}_{\mathrm{pH}}$ classes used, with higher increase in productivity in soils with lower $\mathrm{K} / \mathrm{CTC}_{\mathrm{pH} 7}$ ratio. In the ten-year average, the DMEE was always greater than U\$ 100.00 and higher in soils with $\mathrm{CEC}_{\mathrm{pH}}>15.0 \mathrm{cmol}_{\mathrm{c}} \mathrm{dm}^{-3}$.
\end{abstract}

Index terms: Oryza sativa, calibration, economic efficiency, fertilizer recommendation, CEC saturation.

\section{Introdução}

No Rio Grande do Sul, o arroz (Oryza sativa L.) irrigado é produzido nas regiões Fronteira Oeste, Campanha, Planície Costeira Interna, Planície Costeira Externa, Zona Sul e Depressão Central (Oliveira, 2006). O cultivo do cereal concentra-se na metade sul do Estado, principalmente em razão do relevo favorável e da abundância de mananciais hídricos, com área de 5,4 milhões de hectares apta ao cultivo do arroz (Pinto et al., 2004). Essa área compreende grande diversidade de solos e materiais de origem, e a produção do cereal distribui-se pelas quatro províncias geomorfológicas do Estado: Planalto, Depressão Periférica, Escudo Sul-Rio-Grandense e Planície Costeira (Streck et al., 2008). De modo geral, os solos de terras baixas desenvolveram-se sobre sedimentos e apresentam grande heterogeneidade quanto à composição granulométrica e mineralógica (Klamt et al., 1985). Essa diversidade de solos dificulta recomendações de adubação (Meurer et al., 1996) e o entendimento da resposta da cultura a fertilizações (Castilhos et al., 2002).

A demanda por potássio pelo arroz irrigado é tão ou mais elevada que a por nitrogênio, e chega a $51 \mathrm{~kg}$ 
de $\mathrm{K}_{2} \mathrm{O}$ por tonelada de grãos produzidos (Yoshida, 1981). No entanto, o conteúdo desse elemento nos grãos é relativamente baixo $\left(3,0\right.$ a $4,0 \mathrm{~kg}$ de $\mathrm{K}_{2} \mathrm{O}$ por tonelada), o que indica que a maior parte do nutriente absorvido pela planta retorna ao sistema (De Datta, 1983). Normalmente, utiliza-se o teor trocável de K como índice para o diagnóstico da disponibilidade do nutriente no solo e como critério para recomendação de adubação potássica. Contudo, estudos de calibração da fertilização potássica para a cultura do arroz no Sul do Brasil não encontraram forte relação entre o K extraível pelo método Mehlich-1 e o rendimento da cultura, tanto no sistema de semeadura em solo seco (Machado, 1993) como no pré-germinado (Petrini et al., 2004). A utilização de sais neutros ou de resinas de troca catiônica também não tem sido eficaz para prever a disponibilidade desse nutriente para a cultura do arroz irrigado, conforme constatado por Castilhos \& Meurer (2002) e Nachtigall \& Raij (2005).

O teor de potássio no solo, extraído com sais neutros ou com ácidos diluídos, apesar de ser usado no Brasil para o diagnóstico da disponibilidade do nutriente, não tem boa correlação com o desempenho do arroz irrigado porque a forma trocável pode não ser a única fonte de suprimento do nutriente para as plantas (Castilhos \& Meurer, 2002; Melo et al., 2004; Fraga et al., 2009; Kaminski et al., 2010). Assim, métodos que avaliam apenas uma forma de K, como a trocável, refletem uma medida parcial da disponibilidade do nutriente no solo (Grimme \& Nemeth, 1979). Em solos ricos em minerais micáceos, o conteúdo total de K é naturalmente elevado, enquanto, em solos cauliníticos, o conteúdo varia de alto a baixo. Esse conteúdo, porém, não está fortemente associado ao K extraído por Mehlich-1, e isso diminui a confiabilidade da recomendação da adubação com base nas classes de disponibilidade do nutriente no solo (Brunetto et al., 2005).

Nesse sentido, a inclusão de outros atributos de solo, como a capacidade de troca catiônica (CTC), por exemplo, pode contribuir para aumentar a capacidade preditiva dos métodos de avaliação. No Brasil, algumas publicações utilizam a CTC do solo a pH 7,0 $\left(\mathrm{CTC}_{\mathrm{pH} 7}\right)$, para a recomendação de adubação potássica. O Manual de adubação e de calagem dos Estados do Rio Grande do Sul e de Santa Catarina (2004) considera a $\mathrm{CTC}_{\mathrm{pH} 7}$ um fator relevante na avaliação da disponibilidade de $\mathrm{K}$, cujos valores críticos no solo são de 45, 60 e $90 \mathrm{mg} \mathrm{dm}^{-3}$, para solos com valores de $\mathrm{CTC}_{\mathrm{pH} 7}$ inferiores a 5,0, (baixa), entre 5,0 e 15 (média) e superiores a
$15 \mathrm{cmol}_{\mathrm{c}} \mathrm{dm}^{-3}$ (alta), respectivamente. Da mesma forma, na região do Cerrado brasileiro, Vilela et al. (2004) propõem o nível crítico de $31 \mathrm{mg} \mathrm{dm}^{-3}$ para solos com $\mathrm{CTC}_{\mathrm{pH}}$ inferior a $4,0 \mathrm{cmol}_{\mathrm{c}} \mathrm{dm}^{-3}$, e de $51 \mathrm{mg} \mathrm{dm}^{-3}$, para solos com $\mathrm{CTC}_{\mathrm{pH} 7}$ superior a $4,0 \mathrm{cmol}_{\mathrm{c}} \mathrm{dm}^{-3}$.

Em decorrência da alta produtividade do arroz irrigado por inundação e da resposta frequente dessa cultura à adubação, no Rio Grande do Sul, as recomendações de adubação no estado têm-se ajustado a diferentes expectativas de produtividade (Genro Junior et al., 2010). A partir de 2007, houve a reformulação das recomendações de adubação potássica (Congresso Brasileiro de Arroz Irrigado \& Reunião da Cultura do Arroz Irrigado, 2007), que passaram a considerar diferentes níveis críticos e faixas de interpretação do teor de potássio, de acordo com a $\mathrm{CTC}_{\mathrm{pH} 7}$ do solo. Esse tipo de recomendação considera que a disponibilidade do nutriente depende da relação entre o $\mathrm{K}$ trocável (Mehlich-1) e a quantidade de cargas negativas do solo (relação $\mathrm{K} / \mathrm{CTC}_{\mathrm{pH}}$ ), e que o valor crítico dessa relação está na faixa entre 2 e 3,5\% da $\mathrm{CTC}_{\mathrm{pH} 7}$. Nesse sentido, Fraga et al. (2009) relatam que a capacidade de suprimento de $\mathrm{K}$ no tempo é determinada, predominantemente, pela saturação por $\mathrm{K}$ no complexo de troca (K/CTC $\left.\mathrm{pH}_{7}\right)$, mas, também, pelo suprimento de formas não trocáveis.

O objetivo deste trabalho foi avaliar a resposta do arroz irrigado por inundação à aplicação de doses de potássio, conforme a capacidade de troca catiônica (CTC) do solo.

\section{Material e Métodos}

O trabalho foi desenvolvido nas safras agrícolas de 2005/2006 e 2006/2007, em oito locais por ano agrícola. Em ambas as safras, os experimentos foram implantados em diferentes regiões arrozeiras do Rio Grande do Sul, tendo-se procurado contemplar as mais importantes classes de solos de terras baixas, provenientes de diversos materiais de origem (Tabela 1). Os solos avaliados foram divididos em duas faixas de $\mathrm{CTC}_{\mathrm{pH} 7}$ na camada de $0-20 \mathrm{~cm}$ : até $15 \mathrm{cmol}_{\mathrm{c}} \mathrm{dm}^{-3}$ em 12 locais e superior a $15 \mathrm{cmol}_{\mathrm{c}} \mathrm{dm}^{-3}$ em quatro locais (Tabela 2). Os tratamentos constaram de doses crescentes de potássio: 0 (testemunha), 30, 60, 90 e $180 \mathrm{~kg} \mathrm{ha}^{-1}$, nos solos com $\mathrm{CTC}_{\mathrm{pH} 7}$ de até $15 \mathrm{cmol}_{\mathrm{c}} \mathrm{dm}^{-3}$; e de $0,60,90,180$ e $240 \mathrm{~kg} \mathrm{ha}^{-1}$, nos solos com $\mathrm{CTC}_{\mathrm{pH} 7}$ superior a $15 \mathrm{cmol}_{\mathrm{c}} \mathrm{dm}^{-3}$. Em 2005/2006, 
utilizou-se a cultivar IRGA 417, exceto em Camaquã e em Uruguaiana I, onde se utilizou a cultivar IRGA 422CL, em razão da alta infestação dessas áreas por arroz vermelho. $\mathrm{Na}$ safra seguinte, a cultivar utilizada foi a IRGA 422CL, exceto em Cachoeira do Sul e Santa Vitória do Palmar II, onde foi utilizada a cultivar IRGA 417, e em Santa Vitória do Palmar III, em que se utilizou a cultivar BR-IRGA 410.

Em todas as áreas a semeadura foi realizada em linha e no sistema de cultivo mínimo. Como os experimentos foram semeados em áreas de lavouras comerciais, as épocas de semeadura seguiram a dinâmica adotada nas diferentes propriedades. Entretanto, todas as áreas experimentais foram semeadas nas épocas consideradas ideais (Congresso Brasileiro de Arroz Irrigado \& Reunião da Cultura do Arroz Irrigado, 2005). A densidade de semeadura foi de $100 \mathrm{~kg} \mathrm{ha}^{-1}$ de sementes, em todos os locais. As sementes foram tratadas com inseticida à base de fipronil, para prevenir a infestação de Oryzophagus oryzae. $O$ controle de plantas daninhas foi feito com herbicidas específicos, aplicados no sub-período de desenvolvimento $\mathrm{V}_{3}-\mathrm{V}_{4}$ (Counce et al., 2000). À exemplo da época de semeadura, as adubações nitrogenada e fosfatada seguiram as recomendações para a cultura, para expectativa de rendimento superior a $9 \mathrm{Mg} \mathrm{ha}^{-1}$ (Congresso Brasileiro de Arroz Irrigado \& Reunião da Cultura do Arroz Irrigado, 2005). O fósforo foi aplicado a lanço, juntamente com o potássio, imediatamente após a semeadura, e o nitrogênio foi fracionado em duas aplicações, com $66 \%$ da dose recomendada no sub-período $\mathrm{V}_{3}-\mathrm{V}_{4}$ e o restante por ocasião da diferenciação do primórdio floral.

Os experimentos foram realizados em parcelas de $15,5 \mathrm{~m}^{2}(5 \times 3,1 \mathrm{~m})$, com espaçamento de $0,5 \mathrm{~m}$ entre parcelas e quatro repetições. A colheita de grãos foi realizada em área útil de $5 \mathrm{~m}^{2}$ por parcela. $\mathrm{O}$ material colhido foi processado em trilhadora estacionária, e os grãos foram limpos com peneira e pesados. A massa de grãos foi corrigida para a umidade de $13 \%$.

Ajustou-se a produtividade de grãos às doses aplicadas de potássio por meio de análises de regressão, nos dois grupos de solos avaliados $\left(\mathrm{CTC}_{\mathrm{pH} 7}\right.$ maior ou menor que $\left.15 \mathrm{cmol}_{\mathrm{c}} \mathrm{dm}^{-3}\right)$. Avaliou-se, também, o incremento da produtividade em função do aumento na razão $\mathrm{K} / \mathrm{CTC}_{\mathrm{pH} 7}$ no solo.

A partir das equações de regressão e dos dados de preço do fertilizante e do arroz durante dez anos de produção (de 2003 a 2012), foram calculadas as doses de máxima eficiência técnica (DMET) e econômica (DMEE) de potássio, para as áreas avaliadas. A DMET foi obtida pela derivação das equações de regressão

Tabela 1. Classes dos solos de diferentes locais e safras agrícolas e seus respectivos materiais de origem nas diferentes regiões arrozeiras do Rio Grande do Sul.

\begin{tabular}{|c|c|c|c|}
\hline Local & Classe $^{(1)}$ & $\begin{array}{c}\text { Material } \\
\text { de origem }\end{array}$ & $\begin{array}{c}\text { Região } \\
\text { arrozeira }^{(2)}\end{array}$ \\
\hline & & Safra $2005 / 2006$ & \\
\hline Cachoeirinha I & Gleissolo Háplico eutrófico arênico & Sedimentos aluviais & Planície Costeira Interna \\
\hline Camaquã I & Planossolo Háplico eutrófico arênico & Sedimentos aluviais & Planície Costeira Interna \\
\hline Cachoeira do Sul I & Planossolo Háplico eutrófico arênico & Sedimentos de rochas & Depressão Central \\
\hline Santa Vitória do Palmar I & Chernossolo Argilúvico carbonático & Sedimentos aluviais & Zona Sul \\
\hline Uruguaiana I & Chernossolo Ebânico carbonático & Basalto & Fronteira Oeste \\
\hline Uruguaiana II & Neossolo Litólico eutrófico & Basalto & Fronteira Oeste \\
\hline Dom Pedrito I & Planossolo Háplico eutrófico & Siltitos & Campanha \\
\hline \multirow[t]{2}{*}{ Dom Pedrito II } & Chernossolo Argilúvico órtico & Folhelhos & Campanha \\
\hline & & Safra $2006 / 2007$ & \\
\hline Viamão & Planossolo Háplico eutrófico arênico & Sedimentos arenosos & Planície Costeira Interna \\
\hline Mostardas & Neossolo Quartzarênico hidromórfico & Sedimentos arenosos & Planície Costeira Externa \\
\hline Cachoeirinha II & Gleissolo Háplico eutrófico típico & Sedimentos aluviais & Planície Costeira Interna \\
\hline Camaquã II & Planossolo Háplico eutrófico típico & Sedimentos aluviais & Planície Costeira Interna \\
\hline Cachoeira do Sul II & Planossolo Háplico eutrófico típico & Sedimentos de rochas & Depressão Central \\
\hline Santa Vitória do Palmar II & Chernossolo Argilúvico carbonático & Sedimentos aluviais & Zona Sul \\
\hline Santa Vitória do Palmar III & Planossolo Háplico eutrófico típico & Sedimentos aluviais & Zona Sul \\
\hline Santa Vitória do Palmar IV & Planossolo Háplico eutrófico típico & Sedimentos aluviais & Zona Sul \\
\hline
\end{tabular}

${ }^{(1)}$ De acordo com a classificação brasileira de solos (Santos et al., 2006). ${ }^{(2)}$ Denominação do Instituto Rio Grandense do Arroz (Oliveira, 2006). 
e igualando-as a zero. Para o cálculo da DMEE de potássio (Xor), foi utilizado, além das funções de produção, o preço de venda do arroz, nos meses de abril, entre 2003 e 2012 (Tabela 3), tendo-se determinado o lucro líquido ao se considerar as receitas e os custos totais (fixos + operacionais) dos cultivos.

Tabela 2. Potássio disponível, capacidade de troca de cátions a pH $7,0^{(1)}\left(\mathrm{CTC}_{\mathrm{pH} 7}\right)$ e razão $\mathrm{K} / \mathrm{CTC}_{\mathrm{pH} 7}$ no solo (camada 0-20 cm), em diferentes locais e safras agrícolas.

\begin{tabular}{lccc}
\hline Local & $\begin{array}{c}\mathrm{K} \\
\left(\mathrm{mg} \mathrm{dm}^{-3}\right)\end{array}$ & $\begin{array}{c}\mathrm{CTC}_{\mathrm{pH} 7} \\
\left(\mathrm{cmol}_{\mathrm{c}} \mathrm{dm}^{-3}\right)\end{array}$ & $\begin{array}{c}\mathrm{K} / \mathrm{CTC}_{\mathrm{pH} 7} \\
(\%)\end{array}$ \\
\hline Cachoeirinha I & \multicolumn{3}{c}{ Safra $2005 / 2006$} \\
Camaquã I & 59 & 5,6 & 2,0 \\
Cachoeira do Sul I & 37 & 8,3 & 1,8 \\
Santa Vitória do Palmar I & 59 & 10,3 & 0,9 \\
Uruguaiana I & 120 & 23,0 & 1,3 \\
Uruguaiana II & 76 & 15,6 & 1,3 \\
Dom Pedrito I & 139 & 19,8 & 1,2 \\
Dom Pedrito II & 122 & 36,5 & 0,8 \\
\hline & & Safra $2006 / 2007$ & \\
Viamão & 44 & 4,1 & 2,7 \\
Mostardas & 89 & 5,9 & 3,8 \\
Cachoeirinha II & 30 & 6,7 & 1,1 \\
Camaquã II & 72 & 7,0 & 2,3 \\
Cachoeira do Sul II & 43 & 7,5 & 1,5 \\
Santa Vitória do Palmar II & 58 & 10,7 & 1,4 \\
Santa Vitória do Palmar III & 59 & 5,7 & 2,7 \\
Santa Vitória do Palmar IV & 55 & 5,0 & 2,8 \\
\hline
\end{tabular}

(1)Determinação laboratorial de acordo com Tedesco et al. (1995).

Tabela 3. Preço de cloreto de potássio(1), valores de venda

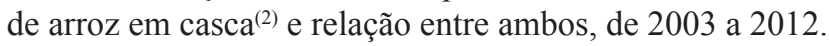

\begin{tabular}{lccc}
\hline Ano & KCl & Arroz & Relação KCl/arroz \\
\hline 2003 & $-----($ U por tonelada)------ & \\
2004 & 113 & 182 & 0,62 \\
2005 & 120 & 222 & 0,54 \\
2006 & 148 & 170 & 0,87 \\
2007 & 180 & 154 & 1,17 \\
2008 & 178 & 197 & 0,90 \\
2009 & 478 & 308 & 1,55 \\
2010 & 745 & 243 & 3,07 \\
2011 & 314 & 299 & 1,07 \\
2012 & 414 & 222 & 1,86 \\
\hline Média & 469 & 262 & 1,79 \\
\hline
\end{tabular}

(1)Preços relativos ao mês de abril de cada ano (The World Bank, 2013). ${ }^{(2)}$ Média aritmética da cotação no mês de abril de cada ano para: arroz longo fino Tipo 1, com 58\% de grãos inteiros; e Tipo 2, com 49 a $51 \%$ de grãos inteiros. Os preços não foram atualizados por nenhum índice, tendo sido cotados pelo valor médio mensal da moeda norteamericana, valor de venda (Instituto Rio Grandense do Arroz, 2013).

\section{Resultados e Discussão}

Os teores de potássio disponível (Mehlich-1) nos diferentes solos e locais variaram de 30 a $139 \mathrm{mg} \mathrm{dm}^{-3}$ (Tabela 2), o que era esperado, pela grande variação nos materiais de origem (Tabela 1). Contudo, a saturação do complexo sortivo do solo por $\mathrm{K}\left(\mathrm{K} / \mathrm{CTC}_{\mathrm{pH}}\right)$ apresentou menor variação, de 0,8 a $3,8 \%$. O maior valor de saturação ocorreu com um teor intermediário de $89 \mathrm{mg} \mathrm{dm}^{-3}$ de K disponível, no Neossolo Quartzarênico hidromórfico típico, que apresenta $5,9 \mathrm{cmol}_{\mathrm{c}} \mathrm{dm}^{-3}$ de $\mathrm{CTC}_{\mathrm{pH} 7}$ considerada relativamente baixa. Já no Chernossolo Háplico órtico vertissólico, que apresenta elevada $\mathrm{CTC}_{\mathrm{pH}}$ de $36,5 \mathrm{cmol}_{\mathrm{c}} \mathrm{dm}^{-3}$, constatou-se que o maior valor de $122 \mathrm{mg} \mathrm{dm}^{-3} \mathrm{de} \mathrm{K}$ disponível resultou na menor saturação $(0,8 \%)$ observada.

Portanto, o agrupamento dos solos em função das classes de $\mathrm{CTC}_{\mathrm{pH} 7}$ pode ser uma maneira eficiente de se melhorar a calibração na recomendação de adubação, por proporcionar curvas de resposta bem ajustadas (Figura 1). Verificou-se resposta quadrática do arroz à aplicação de doses de potássio, em faixas, em ambas as classes de $\mathrm{CTC}_{\mathrm{pH}}$. Esse resultado está de acordo com a interpretação da disponibilidade de potássio em função da $\mathrm{CTC}_{\mathrm{pH}}$ proposta pelo Manual de adubação de calagem para os Estados do Rio Grande do Sul e Santa Catarina (2004), baseada em trabalho desenvolvido por Silva \& Meurer (1988). A interpretação dos teores de $\mathrm{K}$ disponível no solo, de acordo com faixas de $\mathrm{CTC}_{\mathrm{pH}}$,

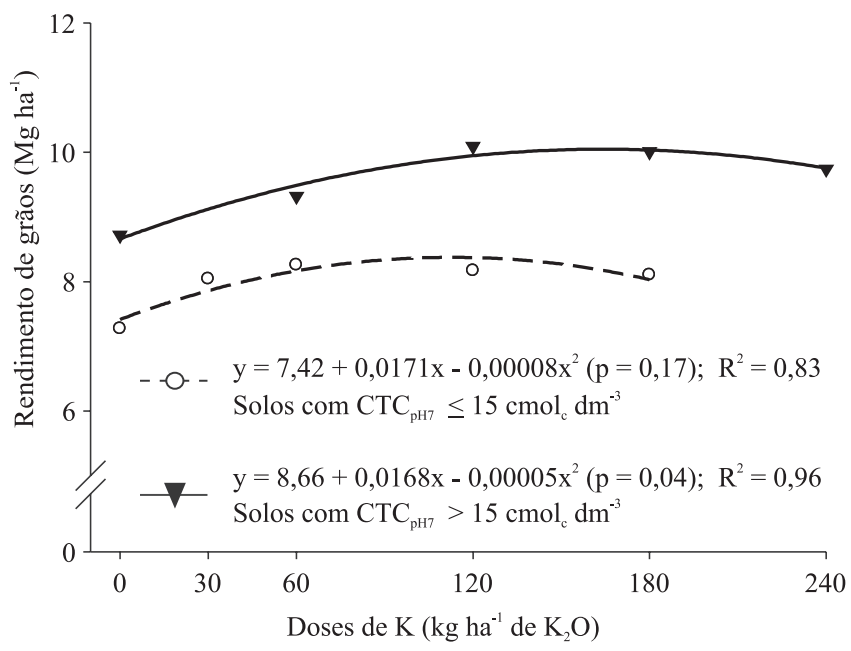

Figura 1. Resposta do arroz irrigado à aplicação de doses de potássio em função da saturação por potássio no complexo de troca $\left(\mathrm{K} / \mathrm{CTC}_{\mathrm{pH} 7}\right)$, em solos das regiões arrozeiras do Rio Grande do Sul. 
já vem sendo adotada pela Sociedade Sul-Brasileira de Arroz Irrigado e consta nas atuais recomendações técnicas para a cultura (Reunião Técnica da Cultura do Arroz Irrigado, 2012).

Embora a resposta à adubação potássica tenha sido sempre positiva, a magnitude dessas respostas e a produtividade do arroz irrigado variaram, tendose observado resposta a doses mais elevadas de $\mathrm{K}$ na classe com alta $\mathrm{CTC}_{\mathrm{pH}}$. Tanto a produtividade quanto a resposta à fertilização foram maiores nos solos com alta CTC (Figura 1). Além disso, a produtividade de grãos da parcela testemunha (sem adição de potássio) também foi maior nos solos com $\mathrm{CTC}_{\mathrm{pH} 7}>15,0 \mathrm{cmol}_{\mathrm{c}} \mathrm{dm}^{-3}$ $\left(8,72 \mathrm{Mg} \mathrm{ha}^{-1}\right)$, em comparação aos solos com menor $\mathrm{CTC}_{\mathrm{pH} 7}\left(7,27 \mathrm{Mg} \mathrm{ha}^{-1}\right)$. A liberação do $\mathrm{K}$ proveniente de formas não trocáveis no solo é influenciada positivamente pelo aumento da difusão (Barber, 1995) e do deslocamento de $\mathrm{K}^{+}$do complexo de troca por $\mathrm{Fe}^{2+}$ e $\mathrm{Mn}^{2+}$, cujas concentrações aumentam na solução do solo em decorrência do alagamento (Ponnamperuma, 1972). Isso pode resultar na disponibilização do K estrutural, presente em feldspatos e micas no solo, e do $\mathrm{K}$ retido nas entrecamadas de argilominerais 2:1 expansivos. Essas formas de K, apesar de consideradas não trocáveis, podem atuar como fontes do nutriente às plantas. Fraga et al. (2009), em estudo com os mesmos solos do presente trabalho, concluíram que a maior capacidade do Neossolo Litólico eutrófico vertissólico, em comparação ao Gleissolo Háplico e ao Planossolo Háplico, ambos eutróficos arênicos, está relacionada à maior presença de feldspatos de potássio e de esmectitas, e que a contribuição de formas não trocáveis de $\mathrm{K}$ para o conteúdo disponível do nutriente no solo sempre ocorre. Da mesma forma, Carmona et al. (2010) relataram importante contribuição dessas formas não trocáveis na nutrição do arroz, mesmo em Planossolos Háplicos, da Planície Costeira Externa do Rio Grande do Sul.

A partir das funções de produção obtidas (Figura 1), foi possível determinar as DMET e DMEE do fertilizante potássico. Diversos autores (Raij et al., 1997; Schlindwein, 2003; Havlin et al., 2005) consideram que a dose de máxima eficiência econômica do nutriente deve estar relacionada a uma produtividade entre 80 e 95\% do rendimento máximo da cultura, possibilitado pela dose de máxima eficiência técnica.

A utilização da relação K/CTC data da década de 1970, com uso no Alabama, EUA, para a interpretação da disponibilidade do nutriente e para o algodão (Cope $\&$ Rouse, 1973). A relação entre esses atributos do solo também pode serútil para estimar a absorção de potássio pelas plantas de sorgo, como verificaram Meurer \& Anghinoni (1993). No presente trabalho, o incremento médio em produtividade do arroz com o uso das doses avaliadas de $\mathrm{K}$ decresce acentuada e linearmente até a saturação do complexo sortivo do solo por $\mathrm{K}$ de 1\% (Figura 2). A partir desse valor de saturação, os incrementos médios na produtividade pela aplicação de K estabilizaram-se em torno de $1 \mathrm{Mg} \mathrm{ha}^{-1}$. Portanto, em valores abaixo de $1 \%$ de saturação, o potencial de resposta do arroz à fertilização potássica é bastante elevado, tendo-se observado incrementos médios na produtividade de até 2,5 $\mathrm{Mg} \mathrm{ha}^{-1}$. Assim, somado aos resultados das curvas de resposta à adubação potássica (Figura 1), a utilização da relação $\mathrm{K} / \mathrm{CTC}_{\mathrm{pH}}$ consiste em um importante indicador do potencial de resposta do arroz à adubação potássica.

Ao longo do período de avaliação (2003 a 2012), observou-se que a DMEE, embora tenha variado, foi maior em solos com $\mathrm{CTC}_{\mathrm{pH} 7}>15,0 \mathrm{cmol}_{\mathrm{c}} \mathrm{dm}^{-3}$ (Figura 3). Na média dos anos, a DMEE para a classe de solos com $\mathrm{CTC}_{\mathrm{pH}}$ superior a $15,0 \mathrm{cmol}_{\mathrm{c}} \mathrm{dm}^{-3}$ foi de $154 \mathrm{~kg} \mathrm{ha}^{-1}$ de $\mathrm{K}_{2} \mathrm{O}$, enquanto, para a classe com menor CTC, a DMEE foi de $98 \mathrm{~kg} \mathrm{ha}^{-1}$ de $\mathrm{K}_{2} \mathrm{O}$. O ano de 2009 foi o que apresentou a menor DMEE, em razão dos maiores custos do fertilizante e dos menores preços do produto (Tabela 3). No entanto, os anos de 2003

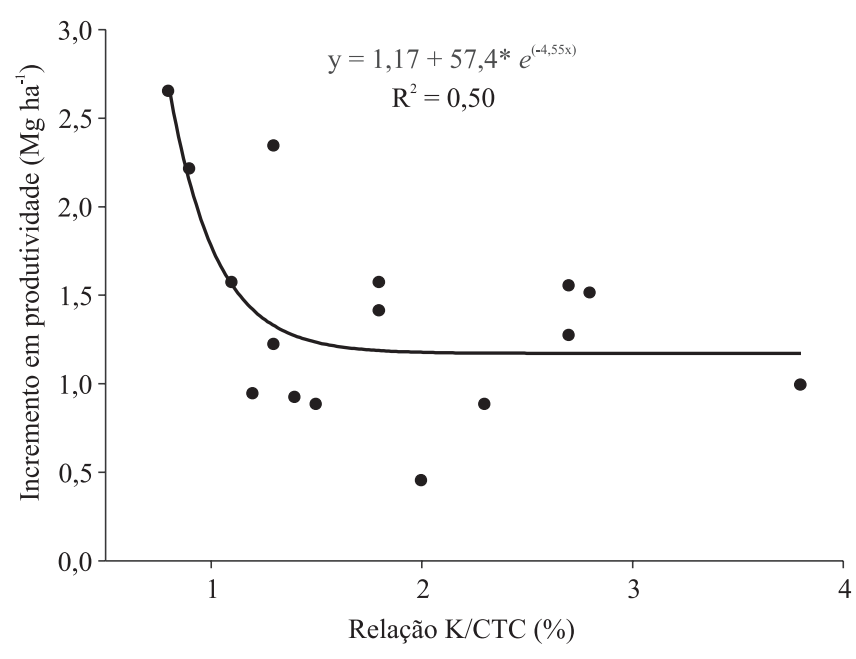

Figura 2. Incremento médio na produtividade do arroz irrigado pela aplicação das diferentes doses de potássio avaliadas, em função da saturação do complexo sortivo do solo por potássio $\left(\mathrm{K} / \mathrm{CTC}_{\mathrm{pH} 7}\right)$.

Pesq. agropec. bras., Brasília, v.48, n.11, p.1481-1488, nov. 2013 DOI: 10.1590/S0100-204X2013001100009 
a 2005 foram os que apresentaram as maiores DMEE (Figura 3). É possível notar uma tendência de queda na DMEE ao longo dos anos, o que evidencia uma crescente valorização do fertilizante em comparação aos preços do cereal.

A produtividade média de grãos alcançada pela aplicação da DMEE manteve-se estável ao longo do tempo (Figura 3). Na média do período avaliado, as produtividades nos solos com $\mathrm{CTC}_{\mathrm{pH} 7}$ maior ou menor que $15,0 \mathrm{cmol}_{\mathrm{c}} \mathrm{dm}^{-3}$ foram de 10,1 e $8,32 \mathrm{Mg} \mathrm{ha}^{-1}$, respectivamente. Apesar das menores produtividades nos solos com menor $\mathrm{CTC}_{\mathrm{pH}}$, os incrementos médios decorrentes da aplicação de potássio foram satisfatórios, de $0,92 \mathrm{Mg} \mathrm{ha}^{-1}$ (Figura 3). Porém, os incrementos médios nos solos com $\mathrm{CTC}_{\mathrm{pH}}>15,0 \mathrm{cmol}_{\mathrm{c}} \mathrm{dm}^{-3}$ foram bem superiores, da ordem de 1,41 $\mathrm{Mg} \mathrm{ha}^{-1}$. De modo geral, esse parâmetro manteve-se estável ao longo dos anos, nas duas classes de CTC avaliadas, exceção feita, novamente, no ano de 2009, que apresentou uma leve redução em relação aos demais.

Entre os parâmetros relacionados à DMEE, o de maior variação, no intervalo avaliado de dez anos, foi o lucro líquido com a aplicação do fertilizante (Figura 3). Deve-se ressaltar, entretanto, que, independentemente do ano e da $\mathrm{CTC}_{\mathrm{pH}}$, a rentabilidade pela aplicação da DMEE foi sempre superior a U\$ 100,00 ha ${ }^{-1}$, inclusive em 2009. Em alguns casos, o lucro líquido foi superior a U\$ 300,00 ha-1, como constatado em 2008 e 2010, nos solos com $\mathrm{CTC}_{\mathrm{pH}}>15,0 \mathrm{cmol}_{\mathrm{c}} \mathrm{dm}^{-3}$. Em todo o período avaliado, a lucratividade líquida obtida pela aplicação da DMEE foi, em média, de U\$ 156,00 $\mathrm{ha}^{-1}$, nos solos com $\mathrm{CTC}_{\mathrm{pH} 7} \leq 15,0 \mathrm{cmol}_{\mathrm{c}} \mathrm{dm}^{-3}$, e de U\$ 237,00 ha ${ }^{-1}$ nos solos com $\mathrm{CTC}_{\mathrm{pH} 7}>15,0 \mathrm{cmol}_{\mathrm{c}} \mathrm{dm}^{-3}$. Essas lucratividades, ao se considerar o custo médio do arroz em casca (Tabela 3), representam um ganho de 13 e 21 sacas de $50 \mathrm{~kg}$ de arroz, respectivamente.
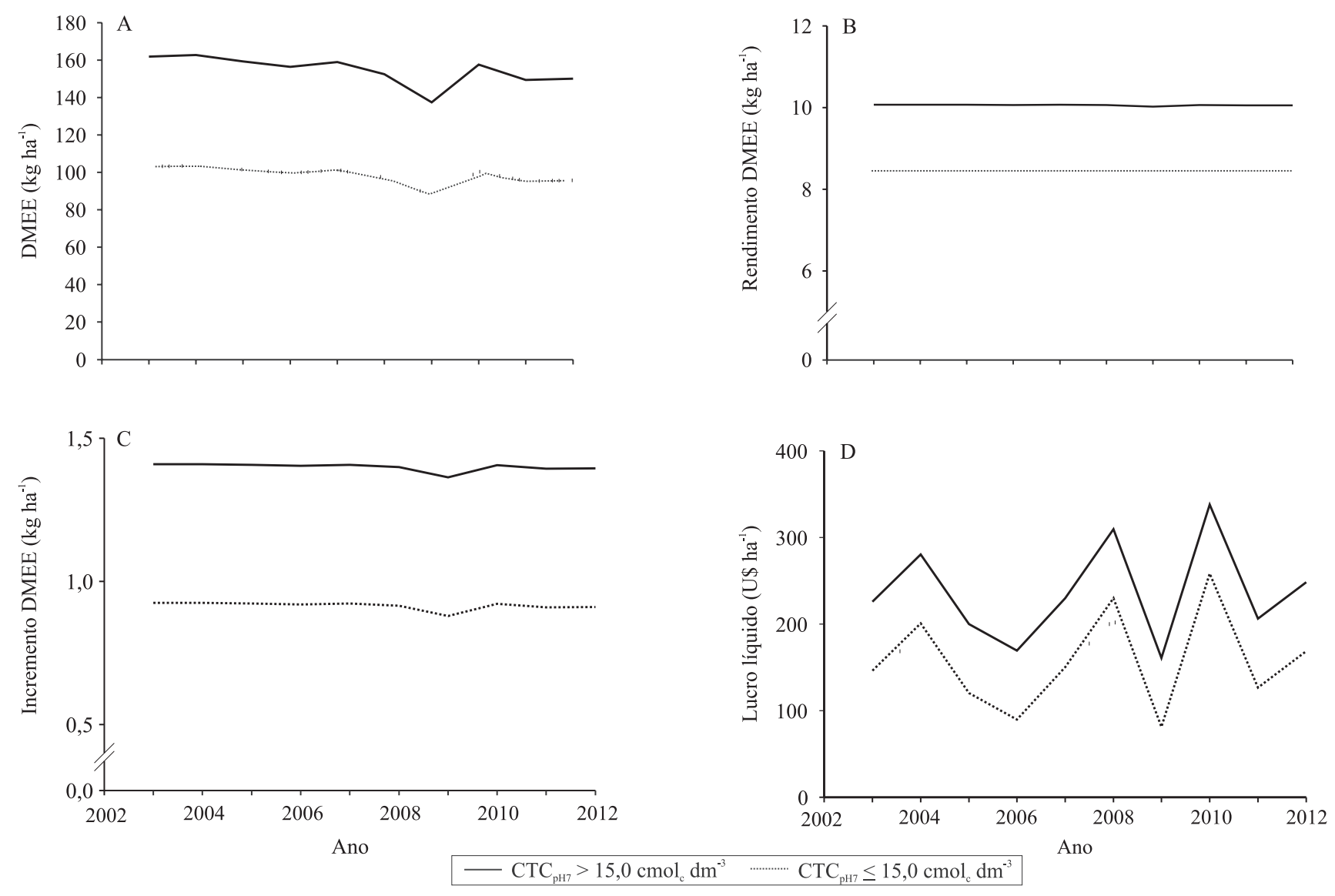

Figura 3. Dose de máxima eficiência econômica (DMEE) de potássio (A), rendimento de grãos de arroz pela aplicação da DMEE (B), incremento da produtividade de grãos pela aplicação da DMEE (C) e lucro líquido obtido com a aplicação da DMEE (D), entre 2003 e 2012, em classes de solo com diferentes faixas de $\mathrm{CTC}_{\mathrm{pH} 7}$. 
Esses resultados são indicativos de que se deve sempre buscar o máximo retorno econômico do arroz irrigado pela aplicação de fertilizante potássico, mesmo em anos cuja relação entre o preço do fertilizante e do produto seja alta.

\section{Conclusões}

1. A saturação do complexo sortivo do solo por K, representada pela relação $\mathrm{K} / \mathrm{CTC}_{\mathrm{pH}}$, pode ser utilizada para estimar o potencial e a magnitude da resposta do arroz irrigado à fertilização potássica, em solos com ampla faixa de capacidade de troca de cátions.

2. A dose de máxima eficiência econômica de potássio é maior nos solos com $\mathrm{CTC}_{\mathrm{pH} 7}>15,0 \mathrm{cmol}_{\mathrm{c}} \mathrm{dm}^{-3}$.

3. Independentemente do custo do fertilizante, do ano agrícola e da $\mathrm{CTC}_{\mathrm{pH}}$ avaliadas, a aplicação da dose de máxima eficiência econômica de potássio é uma prática recomendável, tendo em vista que o lucro líquido decorrente foi sempre positivo e superior a U\$ $100,00 \mathrm{ha}^{-1}$.

\section{Referências}

BARBER, S.A. Soil nutrient bioavailability: a mechanistic approach. $2^{\text {nd }}$ ed. New York: J. Wiley, 1995. 414p.

BRUNETTO, G.; GATIBONI, L.C.; SANTOS, D.R. dos; SAGGIN, A.; KAMINSKI, J. Nível crítico e resposta das culturas ao potássio em um Argissolo sob sistema plantio direto. Revista Brasileira de Ciência do Solo, v.29, p.569-571, 2005. DOI: 10.1590/S010006832005000400009.

CARMONA, F. de C.; ANGHINONI, I.; HOLZSCHUH, M.J.; ANDRIGHETTI, M.H. Cation dynamics in soils with different salinity levels growing irrigated rice. Revista Brasileira de Ciência do Solo, v.34, p.1851-1863, 2010. DOI: 10.1590/ S010006832010000600009.

CASTILHOS, R.M.; MEURER, E.J.; KÄMPF, N.; PINTO, L.F.S. Mineralogia e fontes de potássio em solos no Rio Grande do Sul cultivados com arroz irrigado. Revista Brasileira de Ciência do Solo, v.26, p.579-587, 2002.

CASTILHOS, R.M.V.; MEURER, E.J. Suprimento de potássio de solos do Rio Grande do Sul para arroz irrigado por alagamento. Revista Brasileira de Ciência do Solo, v.26, p.977-982, 2002.

CONGRESSO BRASILEIRO DE ARROZ IRRIGADO, 4.; REUNIÃO DA CULTURA DO ARROZ IRRIGADO, 26., 2005, Santa Maria, RS. Arroz irrigado: recomendações técnicas da pesquisa para o Sul do Brasil. Novos caminhos para a produção de arroz irrigado no Brasil. Santa Maria: SOSBAI, 2005. 159p.

CONGRESSO BRASILEIRO DE ARROZ IRRIGADO, 5.; REUNIÃO DA CULTURA DO ARROZ IRRIGADO, 27., 2007,
Pelotas. Arroz irrigado: recomendações técnicas da pesquisa para o Sul do Brasil. Pelotas: SOSBAI, 2007. 154p.

COPE, J.T.; ROUSE, R.D. Interpretation of soil test results. In: WALSH, L.M.; BEATON, J.D. (Ed). Soil testing and plant analysis. Madison: Soil Science Society of America, 1973. p.2334.

COUNCE, P.A.; KEISLING, T.C.; MITCHELL, A.J. A uniform, objective, and adaptive system for expressing rice development. Crop Science, v.40, p.436-443, 2000. DOI: 10.2135/ cropsci2000.402436x.

DE DATTA, S.K. Principles and practices of rice production. New York: J. Wiley, 1981. 618p.

FRAGA, T.I.; GENRO JUNIOR, S.A.; INDA, A.V.; ANGHINONI, I. Suprimento de potássio e mineralogia de solos de várzea sob cultivos sucessivos de arroz irrigado. Revista Brasileira de Ciência do Solo, v.33, p.497-506, 2009. DOI: 10.1590/ S010006832009000300003.

GENRO JUNIOR, S.A.; MARCOLIN, E.; ANGHINONI, I. Eficácia das recomendações de adubação para diferentes expectativas de produtividade de arroz irrigado por inundação. Revista Brasileira de Ciência do Solo, v.34, p.1667-1675, 2010. DOI: $10.1590 / \mathrm{S} 010006832010000500019$.

GRIMME, H.; NEMETH, K. The evaluation of soil K status by means of soil testing. In: CONGRESS OF THE INTERNATIONAL POTASH INSTITUTE, 11., 1978, Bern. Proceedings... Bern: International Potash Institute, 1979. p.99-108.

HAVLIN, J.L.; BEATON, J.D.; TISDALE, S.L.; NELSON, W.L. Soil fertility and fertilizers: an introduction to nutrient management. $7^{\text {th }}$ ed. New Jersey: Prentice Hall, 2005. 515p.

INSTITUTO RIO GRANDENSE DO ARROZ. Série histórica de preços de arroz em casca. Disponível em: <http://www.irga. rs.gov.br/upload/20131014084112precos_arroz_serie_historica_ casca_t1_58_set_2013.pdf $>$. Acesso em: 18 out. 2013.

KAMINSKI, J.; MOTERLE, D.F.; RHEINHEIMER, D. dos S.; GATIBONI, L.C.; BRUNETTO, G. Potassium availability in a hapludalf soil under long term fertilization. Revista Brasileira de Ciência do Solo, v.34, p.783-791, 2010. DOI: 10.1590/ S010006832010000300020.

KLAMT, E.; KÄMPF, N.; SCHNEIDER, P. Solos de várzea no Estado do Rio Grande do Sul. Porto Alegre: UFRGS, 1985. 43p. (UFRGS. Boletim técnico de solos, 4).

MACHADO, M.O. Adubação e calagem para a cultura do arroz irrigado no Rio Grande do Sul. Pelotas: Embrapa-CPATB, 1993. 63p. (Embrapa-CPATB. Boletim de pesquisa, 2).

MANUAL de adubação e de calagem para os Estados do Rio Grande do Sul e Santa Catarina. 10.ed. Porto Alegre: Sociedade Brasileira de Ciência do Solo Núcleo Regional Sul Comissão de Química e Fertilidade do Solo, 2004. 400p.

MELO, G.W.; MEURER, E.J.; PINTO, L.F.S. Fontes de potássio em solos distroférricos cauliníticos originados de basalto no Rio Grande do Sul. Revista Brasileira de Ciência do Solo, v.28, p.597-603, 2004. DOI: 10.1590/S010006832004000400002. 
MEURER, E.J.; ANGHINONI, I. Disponibilidade de potássio e sua relação com parâmetros de solo. Revista Brasileira de Ciência do Solo, v.17, p.377-382, 1993.

MEURER, E.J.; KAMPF, N.; ANGHINONI, I. Fontes potenciais de potássio em alguns solos do Rio Grande do Sul. Revista Brasileira de Ciência do Solo, v.20, p.41-47, 1996.

NACHTIGALL, G.R.; RAIJ, B. van. Análise e interpretação do potássio no solo. In: SIMPÓSIO SOBRE POTÁSSIO NA AGRICULTURA BRASILEIRA, 2., 2004, São Pedro. Potássio na agricultura brasileira: anais... Piracicaba: Associação Brasileira para Pesquisa da Potassa e do Fosfato, 2005. p.93-118.

OLIVEIRA, C.F. (Coord.). Censo da lavoura de arroz irrigado do Rio Grande do Sul safra 2004/05. Porto Alegre: IRGA, 2006. $122 \mathrm{p}$.

PETRINI, J.A.; FRANCO, D.F.; SOUZA, P.R. de; BACHA, R.E.; TRONCHONI, J.G. Sistema de cultivo de arroz pré-germinado e transplante de mudas. In: GOMES, A. da S.; MAGALHÃES JÚNIOR, A.M. de (Ed.). Arroz irrigado no Sul do Brasil. 21.ed. Pelotas: Embrapa Clima Temperado; Brasília: Embrapa Informação Tecnológica, 2004. p.387-416.

PINTO, L.F.S.; LAUS NETO, J.A.; PAULETTO, E.A. Solos de várzea do Sul do Brasil cultivados com arroz irrigado. In: GOMES, A. da S.; MAGALHÃES JÚNIOR, A.M. de (Ed.). Arroz irrigado no Sul do Brasil. 21.ed. Pelotas: Embrapa Clima Temperado; Brasília: Embrapa Informação Tecnológica, 2004. p.75-96.

PONNAMPERUMA, F.N. The chemistry of submerged soils. Advances in Agronomy, v.24, p.29-96, 1972. DOI: 10.1016/ S00652113(08)606331.

RAIJ, B. van; CANTARELLA, H.; QUAGGIO, J.A.; FURLANI, A.M.C. Recomendações de adubação de calagem para o Estado de São Paulo. 2.ed. rev. e atual. Campinas: Instituto Agronômico, 1997. 285p. (Boletim técnico, 100).
REUNIÃO TÉCNICA DA CULTURA DO ARROZ IRRIGADO, 29., 2012, Gravatal. Arroz irrigado: recomendações técnicas da pesquisa para o Sul do Brasil. Itajaí: Sosbai: EPAGRI: 2012. 179p.

SANTOS, H.G. dos; JACOMINE, P.K.T.; ANJOS, L.H.C. dos; OLIVEIRA, V.A. de; OLIVEIRA, J.B. de; COELHO, M.R.; LUMBRERAS, J.F.; CUNHA, T.J.F. (Ed.). Sistema brasileiro de classificação de solos. 2.ed. Rio de Janeiro: Embrapa Solos, 2006. 306p.

SCHLINDWIEN, J.A. Calibração de métodos de determinação e estimativa de doses de fósforo e potássio em solos sob sistema plantio direto. 2003. 169p. Tese (Doutorado) - Universidade Federal do Rio Grande do Sul, Porto Alegre.

SILVA, J.R.J.; MEURER, E.J. Disponibilidade de potássio em solos do Rio Grande do Sul em função da capacidade de troca de cátions. Revista Brasileira de Ciência do Solo, v.12, p.137-142, 1988.

STRECK, E.V.; KÄMPF, N.; DALMOLIN, R.S.D.; KLAMT, E.; NASCIMENTO, P.C. do; SCHNEIDER, P.; GIASSON, E.; PINTO, L.F.S. Solos do Rio Grande do Sul. Porto Alegre: Emater-RS, 2008. 222p.

TEDESCO, J.M.; GIANELLO, C.; BISSANI, C. A.; BOHNEM, H.; VOLKWEISS, S.J. Análise de solo, plantas e outros materiais. 2.ed. rev. e ampl. Porto Alegre: UFRGS, 1995. 174p. (UFRGS. Boletim técnico de solos, 5).

THE WORLD BANK. GEM commodities. Available at: <http:// data.worldbank.org/datacatalog/commoditypricedata $>$. Accessed on: 18 Oct. 2013.

VILELA, L.; SOUZA, D.M.G.; SILVA, J.E. Adubação potássica. In: SOUZA, D.M.G. de; LOBATO, E. (Ed.). Cerrados: correção do solo e adubação. 2.ed. Planaltina: Embrapa Cerrados, 2004. p.169-184.

YOSHIDA, S. Fundamentals of rice crop science. Los Baños: International Rice Research Institute, 1981. 269p.

Recebido em 11 de março de 2013 e aprovado em 21 de outubro de 2013 